\title{
ECONOMÍA MORAL Y GESTIÓN ARISTOCRÁTICA EN TIEMPOS DEL QUIJOTE*
}

\author{
BARTOLOMÉ YUN CASALILLA \\ Instituto Universitario Europeo de Florencia ${ }^{\mathrm{a}}$
}

\begin{abstract}
RESUMEN
Este artículo postula el estudio conjunto de las historias intelectual y económica. Las representaciones mentales afectan a las decisiones y variables económicas, al tiempo que las realidades económicas influyen en la evolución de las ideas. Esto se ilustra con el caso de la nobleza castellana y su gestión de los patrimonios. Ésta venía determinada en gran parte por la «economía moral» del grupo, que venía a justificar su lugar privilegiado en la sociedad. Sin embargo, en la Edad Moderna nuevas ideas y dificultades económicas erosionaron esos conceptos y actitudes, conduciendo a un creciente interés de los nobles por una gestión eficiente de sus propiedades. El delicado equilibrio entre ganancia y prestigio -a su vez un medio indirecto de conseguir riqueza-, así como la omnipresencia de preocupaciones religiosas, obstaculizan la correcta visión de la situación real y de su evolución, no por ello menos necesaria.
\end{abstract}

Me gustaría dedicar este ensayo a la memoria de Pierre Vilar, cuyo «El tiempo del 'Quijote'» (1974), constituye todavía una de las obras más sugestivas sobre un tiempo clave en la historia de España.

He querido profundizar en este trabajo en algunas de las cuestiones que recientemente he expuesto en Yun (2004, pp. 428-54). Se trata aquí de mirar desde la ideología y la mentalidad de la época lo que en otros estudios he analizado a partir sobre todo de los condicionantes económicos, sociales y políticos de la gestión señorial, para ir más allá en la comprensión del fenómeno, así como en la realidad social de la alta nobleza de la época de Cervantes.

a Badia Fiesolana, Via dei Roccettini 9, I-50016 San Domenico di Fiesole (FI). Italia. Bartolome.Yun.Casalilla@iue.it 
Palabras clave: historia económica, historia intelectual, nobleza, gestión patrimonial

\begin{abstract}
This article makes a plea for a joint study of intellectual and economic history. Mental perceptions affect economic decisions and variables, while economic realities influence the evolution of ideas. We use the case of Castilian noblemen and their management of landed property to illustrate these interrelations. This was driven to a large extent by the «moral economy» of the group, which provided a moral justification of its privileged place in society. However, during the early modern age new ideas and economic difficulties eroded these concepts and attitudes, and led to an increasing interest of nobility towards an efficient management of their properties. The delicate equilibrium between gains and prestige -intended as an indirect means to acquire wealth- as well as the intermingling of religious worries make it difficult to get a balanced view of the real situation and its evolution, which is none the less necessary.
\end{abstract}

Keywords: economic history, intellectual history, nobility, management of landed property

JEL Classification: N01, N83

«La historia intelectual, al igual que la historia económica y antes que ella, se vuelve imperialista y procura invadir toda la vida social. Es necesario hacer una pausa de vez en cuando para recordar que la forma en que la gente concebía su época no tenía por qué ser igual que la realidad de dicha época.»

E. P. Thompson (1995, pp. 309-10)

\title{
1. INTRODUCCIÓN
}

No hace mucho, en una aguda reflexión sobre las raíces medievales de Europa, Jaques Le Goff hacía de la caballería y el sentido cortés de la sociabilidad y también, más específicamente, del amor cortés- dos de las claves de la sociedad medieval sobre las que se articularía la cultura europea posterior al siglo $\mathrm{xI}^{1}$.

\footnotetext{
${ }^{1}$ Aunque el libro apareció simultáneamente, como todos los de la colección, en varios idiomas, incluidos el castellano y el catalán, cito siempre por la versión italiana. Le Goff (2004, pp. 70 y ss.).
} 
Afirmaciones como la del historiador francés pueden servir para situar a Cervantes, a su don Quijote y, desde luego, a la aristocracia -o a la nobleza, si se prefierede fines del siglo xvi en su propia encrucijada. Porque, en efecto, si algún consenso hay sobre El Quijote, es el referente a cómo la novela refleja la crisis de una serie de valores, los valores de la nobleza europea y, en particular, de su mentalidad caballeresca, que, por ser la de los del grupo dominante, respondía a una crisis social de mayor alcance e intensidad. Podemos dejar a un lado lo que eso significa desde el punto de vista de la historia de Europa y de los cambios que, como subrayara ya hace mucho tiempo P. Hazard (1941), se habrían producido en la conciencia europea -según él- en la segunda mitad del xvir, y que habrían dado lugar al arranque de la modernidad. Pero no es menos cierto que, desde una perspectiva española y, más en particular, desde la perspectiva de la historia económica de España, el fenómeno no puede por menos que obligarnos a la reflexión: ¿Crisis de valores de la nobleza en la Castilla de fines del Xvi? ¿No era ésta el área de Europa para la que con más énfasis se ha hablado de reforzamiento a fines del siglo XVI de las formas de vida nobiliaria? ¿No se ha llegado a hacer de esto incluso uno de los aspectos más directamente relacionados -como causa y como consecuencia al mismo tiempo- con la crisis de fines de siglo que llevaría a la recesión del siglo xvir en muchas áreas de la Península? ¿No se ha considerado esa mentalidad nobiliaria como una de las claves del atraso español?

Nada más lejos de la intención de estas líneas que iniciar aquí una discusión -sin duda tautológica- sobre la importancia de los valores culturales y de las causas materiales en la crisis de fin de siglo y en la recesión. Pero sí que es importante reflexionar sobre las imbricaciones entre ambos aspectos de cara a entender mejor la economía castellana y europea de la época. Tales reflexiones no pueden sino partir de lo que son hoy algunas de las fronteras de la historia económica. Permítaseme comenzar por éstas -de forma muy breve y provisional-, para seguir después con lo que da motivo a este trabajo.

\section{HISTORIAECONÓMICAE HISTORIA CULTURAL. UNAS BREVES REFLEXIO-} NES

Aunque no siempre somos conscientes de ello a la hora de plantear nuestra investigación, no creo descubrir nada nuevo si afirmo que las relaciones entre la evolución cultural y la economía en las distintas sociedades constituyen hoy un aspecto crucial en las explicaciones de los procesos económicos en el pasado. Sin duda, esto es fruto del desarrollo de la historia cultural y, en especial, de la creciente importancia de las visiones que intentan entender la historia social des- 
de el punto de vista de la cultura². Y lo es asimismo de la ampliación y diversificación del tipo de problemas que se plantean los historiadores de la economía.

Desde el mismo corazón de la historia económica más «clásica» se perciben síntomas que no pueden sino augurar -esperémoslo así, al menos- un incremento de esta tendencia. No hace mucho tiempo, historiadores como Temin (1997), tan cercano en su época a la New Economic History, llamaban la atención sobre la necesidad de entender y explicar el desarrollo industrial bajo la consideración de factores relacionados con el mundo de los valores de las distintas sociedades. En su caso -en un discurso que, desde luego, no apoyamos, pero cuya perspectiva no puede dejar de interesarnos-, haciendo hincapié en la importancia de lo que él llamaba «el individualismo propio de la cultura anglosajona» como factor crucial del desarrollo empresarial e industrial. En todo caso, ello le daba pie para abrir de nuevo una perspectiva que, como el mismo Temin recuerda, estaba ya presente en clásicos como Max Weber o Veblen.

$\mathrm{Y}$ no es el anterior sino un ejemplo aislado -y conscientemente elegido de entre lo que para algunos es el núcleo duro de la historia económica- de un proceso más general. Campos tan privilegiados hoy como el de la historia del consumo están alumbrando asimismo formas de entender la relación entre el cambio social y cultural y el desarrollo económico que difieren mucho de lo que ha sido habitual durante mucho tiempo entre nosotros. Desde esa perspectiva, por ejemplo, procesos como las transformaciones culturales experimentadas en el siglo XvIII se han considerado claves para explicar el arranque del crecimiento económico moderno ${ }^{3}$. En otra dimensión, aunque con una aproximación parecida, la creciente importancia de conceptos como el de capital humano a la hora de analizar y explicar el desarrollo económico no ha hecho sino acentuar aún más la necesidad de entender el crecimiento económico como fruto de la evolución cultural de las distintas sociedades, de su capacidad de desarrollar e incorporar conocimientos y técnicas y de su predisposición a hacerlo 4 .

Incluso en lo que se refiere a los grandes hitos del desarrollo económico, como es el caso de la revolución industrial, no faltan las explicaciones - por el contrario,

\footnotetext{
${ }^{2}$ Algunas perspectivas a este respecto se pueden encontrar en diversos trabajos aparecidos recientemente en el American Historical Review. A propósito de los comentarios al libro de V. E. Bonnell y L. Hunt (eds.) (1999).

${ }^{3}$ La bibliografía al respecto es extensísima. Aunque no actualizada, pues con posterioridad ha habido aún avances, se puede ver un estado de la cuestión en mi B. Yun (1999).

${ }^{4}$ El planteamiento, muy antiguo ya, y en ese sentido aún más revelador de lo que decimos, tiene uno de sus pioneros en C. M. Cipolla (1969). Incluso trabajos como el de Landes (1998), quizá discutibles en otros sentidos, han puesto el acento en este tipo de cuestiones. En concreto en este caso, buena parte de sus argumentos descansa en la diferente capacidad de las distintas sociedades para desarrollar e incorporar avances tecnológicos según su mayor o menor grado de tolerancia ideológica y cultural. De hecho, aquí estaría, para el historiador de Harvard, buena parte de las razones del llamado «fracaso ibérico».
} 
son cada vez más frecuentes- que ponen el énfasis en el desarrollo cultural como componente indispensable. Así, en una serie de trabajos recientes, J. Mokyr ha hecho de la Ilustración y el surgimiento de la ciencia moderna ligado a ella, y a una nueva forma de difusión de los avances tecnológicos, el hito clave que explicaría el desarrollo del capitalismo en el siglo XVIII ${ }^{5}$.

Dentro de las posibilidades que ofrece esta relación entre historia cultural e historia económica, me parece que se deben destacar las que arrancan del estudio de los componentes culturales que están siempre detrás del proceso de toma de decisiones que afectan al desarrollo económico. Es en este plano donde se mueve una serie de reflexiones que parten de la teoría del capital humano y, más en particular, del capital en forma de know how y de valores específicos y que pueden servir para explicar la introducción de mejoras -o la falta de ellas- en la esfera productiva y, especialmente, en la esfera empresarial. En ese sentido, y en particular en lo que se refiere a las sociedades del Antiguo Régimen, de códigos culturales y normativos más lejanos de los imperantes en la nuestra, la historia económica tiene un reto que afrontar. Sobre todo porque, como he tenido oportunidad de resaltar en otra ocasión también a propósito de la aristocracia, es en ese plano en el que el proceso de toma de decisiones que directa o indirectamente pueda haber afectado al crecimiento económico, se debe entender en el contexto de sistemas culturales específicos que configuran jerarquías de valores particulares, y que, a su vez, no constituyen sólo o tanto representaciones mentales o normativas teóricas en el sentido que habitualmente las hemos entendido, sino que se encuentran perfectamente insertas en la «experiencia práctica» cotidiana de los individuos ${ }^{6}$.

Es precisamente en ese sentido en el que me permito utilizar el término «economía moral», acuñado por E. P. Thompson hace ya más de treinta años, como clave para entender los comportamientos aristocráticos de la Castilla de la época de Cervantes y sus derivaciones en la forma de gestión de sus patrimonios ${ }^{7}$. Porque, en efecto, para el historiador y activista inglés, tal concepto se sitúa en el plano intermedio y en el entrecruce entre el sistema de valores, a menudo de fuerte componente heredado y, desde luego, contradictorio en sí mismo de una sociedad, y la práctica de un grupo social ${ }^{8}$. En palabras del propio E. P. Thompson

\footnotetext{
${ }^{5}$ Mokyr (2004). Agradezco a Joel Mokyr el haberme permitido consultar este trabajo antes de su publicación.

${ }^{6}$ Yun (2005).

${ }^{7}$ Como ya he recordado en otras ocasiones a la hora de utilizar este término, lo hago consciente de la aversión de su autor a trasponerlo a otros grupos sociales y a otros contextos históricos al de la clase obrera inglesa de los siglos XVIII y XIX, para el que él mismo lo creó. Véase E. P. Thompson (2000).

${ }^{8}$ Para un estudio en un contexto mucho más amplio de las concepciones thompsonianas al respecto y en particular sobre la importancia del concepto de experiencia tal y como lo entendía el historiador inglés, puede verse R. G. Suny (2002).
} 
(1979, p. 317), se trata de ver a los individuos y a su toma de decisiones en el plano de la «dialéctica de la interacción, la dialéctica entre 'economía' y 'valores'» (1979). En otros términos, lo que intento proponer es la necesidad de entender la acción humana que afecta a la economía en el contexto de «experiencias materiales [que] se modelan en formas culturales» o, lo que es lo mismo, entender la acción de los nobles de la época de Cervantes en términos de «elección moral», por usar la expresión de Thompson (1979, p. 315) ${ }^{9}$. Una postura que nos aleja tanto de los tópicos que han visto la acción de la aristocracia a la luz de un supuesto y estático código normativo y de valores, como de interpretaciones en exceso economicistas sobre su racionalidad y criterios de comportamiento.

Un planteamiento como éste exige a su vez analizar la vertiente económica de la cultura y los comportamientos aristocráticos de la época más allá de los estereotipos habituales al respecto. Se impone un estudio de los comportamientos aristocráticos en la encrucijada derivada de la confrontación de valores y prácticas que se sitúa más allá de los estereotipos establecidos por los historiadores y que, a su vez, no son sino abstracciones que registran partes de una realidad, por definición contradictoria internamente.

\section{ENTRE LOS TIPOS IDEALES Y LA REALIDAD. ¿VALORES «ARISTOCRÁTI- COS» VS. VALORES «BURGUESES» EN LA ESPAÑA DEL QUIJOTE?}

Es importante llamar la atención sobre el hecho de que la historia de este período, y el problema al que aludimos, se ha planteado siempre desde la perspectiva de la confrontación de modelos claramente opuestos a los que, a su vez, se atribuían grupos sociales que necesaria y estructuralmente habían de estar siempre enfrentados: la aristocracia -la nobleza, si se quiere- por un lado y las clases mercantiles -o la burguesía, si así se prefiere- por el otro.

Desde luego, basta mirar a las obras que se han ocupado del tema para encontrar rasgos muy precisos -demasiado precisos- de lo que entre nosotros se ha considerado una mentalidad aristocrática. El sentido del honor, reñido por otra parte con las actividades productivas y sobre todo con el comercio; el énfasis en la sangre como criterio de diferenciación social; el rechazo al trabajo; el énfasis en el lujo y la ostentación como forma de manifestación de status que llevaba al derroche, al endeudamiento y a la despreocupación por la gestión de los patrimonios, tan opuestos a los criterios de inversión, etc. Todos ellos se han considerado como valores típicamente aristocráticos muy presentes, dominantes, en la so-

\footnotetext{
${ }^{9}$ Obviamente, ésta es una empresa de más amplio calado, que se sale del propósito y las posibilidades de estas breves páginas. Tan sólo pretendo aquí apuntar, de modo provisional, algunas cuestiones al respecto que enlazan y rectifican trabajos previos.
} 
ciedad europea y sobre todo española de los siglos XVI y xvII. Frente a ellos, la historiografía ha opuesto lo que, a posteriori consideramos los valores de la burguesía. Así, desde Max Weber, Sombart y otros pensadores -parte de los cuales no han hecho sino seguir la estela de los grandes nombres de la Ilustración y particularmente de Adam Smith-, a tales valores se ha opuesto siempre el sentido de la frugalidad y el ascetismo, ligados a las actividades comerciales y a formas de virtú cívica cuya consecuencia inmediata habría de ser el desarrollo económico ${ }^{10}$.

Tal planteamiento, que arranca precisamente de la Ilustración y que se consolida en la historiografía de la revolución liberal burguesa del siglo xix, responde sin duda a una parte de la realidad y da cuenta de importantes dimensiones del proceso histórico. Pero no es menos cierto que éste no constituye el mejor punto de partida para la comprensión de determinados procesos de excepcional relevancia a la hora de explicar las conexiones entre cambio social y económico en el Antiguo Régimen. De hecho, ideas como la, hoy muy criticada, de la «traición de la burguesía», tan aplicada por lo demás al caso de las sociedades ibéricas, se están mostrando como poco operativas desde muchos puntos de vista. Es más, la visión culturalista de la sociedad está llevando a que cada vez más se entienda que no existen valores exclusivos de un grupo social determinado, o de que éstos sean los mínimos o muy dinámicos. Dicho con otras palabras, muchos de los valores y de los componentes de la economía moral de un grupo social determinado pueden ser compartidos de forma normal por capas de la sociedad que no pertenecen a éste.

Por otra parte, es evidente que los grupos sociales se representan y se reformulan a sí mismos de forma continua y sistemática. Al igual que dijera Thompson de la clase obrera inglesa, cuya principal característica es que no existía como tal y de forma predeterminada, sino que se reformuló a sí misma y a sus representaciones en función de su experiencia, la aristocracia del Antiguo Régimen -o, mejor, las aristocracias- se deben entender como un grupo dinámico en constante remodelación de sus componentes, de sus representaciones sociales, de sus imágenes políticas y, por tanto, de su acción social ${ }^{11}$. Esa ha sido precisamente una de las grandes virtudes de un libro de J. Dewald, criticable quizá desde otros puntos de vista, pero que nos ha mostrado cómo muchos de los valores y de los componentes de lo que solemos identificar con el imaginario de la burguesía, tienen como uno de su máximos emisores y promotores a miembros de las aristocracias

\footnotetext{
${ }^{10}$ Tales ideas se pueden ver bien sistematizadas en Sombart, quien no casualmente dedicó sendos estudios, uno al burgués y otro al lujo. Véase sobre todo Sombart (1966 y 1979). Véase una interesante visión o re-visión de estas cuestiones ligando los conceptos de frugalidad, comercio, virtud cívica e intentando repensar los orígenes de la «ética protestante», a la que, como es sabido, se refiriera ya hace tiempo $\mathrm{M}$. Weber, en términos de desarrollo del republicanismo, en Pocock (2002) pp. 526-38.

${ }^{11}$ Thompson, (1980), II, p. 314, entre otras.
} 
europeas de la época -el sentido de la individualidad y de la privacidad, por ejemplo $^{12}-$ lo que quiere decir, obviamente, que ni esos valores se pueden calificar como exclusivamente burgueses, ni a las aristocracias se las puede entender como el grupo estático fiel a sus principios -o a los que nosotros les atribuimos como tales- que muchas veces describimos. En otras palabras, si bien podemos definir tipos ideales que en un momento sirven para estudiar las características sociales y culturales de un determinado grupo social, es claro que la realidad es mucho más dinámica y contradictoria. De hecho, la función de los tipos ideales, tal y como los definiera el propio Max Weber, era la de ser instrumentos analíticos, útiles además para ejercicios de comparación de cara a descubrir una realidad mucho más dinámica, contradictoria y rica de lo que los estereotipos al uso nos puedan hacer suponer ${ }^{13}$.

Desde esa perspectiva se pueden entender bastantes cosas e incluso hacer una crítica a muchas de nuestras asunciones sobre la sociedad castellana -y europea- de la época de Cervantes. Desde luego, no es éste el lugar adecuado para hacerlo, pero sí que es obligado realizar una serie de reflexiones.

La imagen imperante entre los historiadores de la economía y la sociedad hasta ahora ha sido la de un reforzamiento de las formas de vida -y de la mentalidad, se ha dicho- aristocráticas desde las últimas décadas del siglo XVI. Un reforzamiento que, además, no sólo tenía raíces sociales y culturales -la jerarquía de valores predominante-, sino también económicas: las bancarrotas, la incertidumbre económica, la emisión de deuda, la venta de títulos, etc. habrían alentado la búsqueda de valores-refugio más adecuados ${ }^{14}$. El resultado es el de una sociedad de valores aristocráticos inexpugnables sólidos, inamovibles o, en el mejor de los casos, capaces de resistir cualquier embate -y a absorber cualquier tensión- derivado de la acción de otros grupos sociales o del desarrollo ideológico y cultural.

Esta era parte de la realidad. Pero es curioso que historiadores de la cultura, o aquellos que, como Maravall o Cavillac, han estudiado el problema desde otra dimensión, han subrayado precisamente el carácter crítico y contradictorio de la moral social y de las representaciones sociales de la época y, para lo que a nosotros nos interesa, de la «economía moral» predominante, que era, precisamente, la de la aristocracia -o, si se prefiere, en este caso habría que decir la de la nobleza-. Así, si, hace ya bastantes años, el primero puso el acento sobre una crisis -la crisis social del Barroco, en sus propias palabras-, que habría afectado también a los valores aristocráticos, el segundo ha llamado la atención sobre el notable vigor adquirido por otros valores que subrayaban la importancia del trabajo y el reco-

\footnotetext{
${ }^{12}$ Véase fundamentalmente, Dewald (1996), p. 149-187.

${ }^{13}$ Weber (1978).

${ }^{14}$ Se me perdonará no hacer aquí una lista -que sería interminable- de historiadores, entre los cuales seguramente me encuentro, que han planteado las cuestiones de este modo.
} 
nocimiento social del comercio -a los que él llamaba valores «burgueses»- y que a su entender no eran sino manifestaciones de una crisis de los valores nobiliarios $^{15}$. El mismo Quijote habría sido la expresión más palpable de esta situación, como a menudo han puntualizado los historiadores de la literatura ${ }^{16}$. Visiones como éstas dan pie, en todo caso, a un planteamiento más abierto del tema que nos aleje al tiempo de posturas economicistas y de un «culturalismo» basado en una lectura simplista de los textos y que se ajusta más a la tratadística sobre la nobleza que a la realidad.

\section{DE LA RELIGIÓN A LA MORAL ECONÓMICA DE LAARISTOCRACIA}

No es éste el lugar para hacer una descripción de la cultura aristocrática en la época moderna, ni tampoco cabe un análisis del proceso de transformación, mucho más traumático de lo que se ha dado a entender, por el que estaba pasando ésta desde las últimas décadas del siglo xvi, como mínimo. Pero se imponen, en cualquier caso, una serie de reflexiones generales ${ }^{17}$.

Existen una serie de puntos de partida esenciales. Es bien sabido que el imaginario social de la época tenía un fuerte contenido neoplatónico: en la mentalidad de las élites europeas y desde luego de la Monarquía Hispánica, la sociedad terrena no era sino una «sombra» del orden divino, al cual no se ajustaba de modo sistemático, pero del que constituía un reflejo evidente ${ }^{18}$. Como resultado, cada individuo tenía su ubicación social determinada a la que había de responder en sus más mínimos actos. Sus comportamientos, sus formas de consumo y de presentarse en so-

\footnotetext{
${ }^{15}$ Tales ideas están contenidas, de uno u otro modo, en muchos de los textos de Maravall, por ejemplo (2000, pp. 66-7 y otras). Asimismo, y por lo que se refiere al Quijote, es inexcusable citar aquí a Maravall (1948). De Cavillac puede verse, también entre otros, (1994). Ya he manifestado en otra ocasión mi resistencia a plantear el análisis que hace Cavillac en términos de mentalidad burguesa, pero, en todo caso, es evidente que esto no quita valor a su fino análisis: vid. Yun (2004, pp. 428-54). Por desgracia, si bien el análisis de Cavillac ha estado relativamente presente entre los historiadores de la economía, no ha sido ése el caso entre los historiadores de la cultura aristocrática que, sobre todo en los últimos años, se han mantenido en una perspectiva culturalista, ligada muchas veces a la historiografía de Corte y, a su vez, a centenarios y celebraciones millonarias, que han encontrado en la nueva historia de Corte emanada de las ideas de Elias -aunque algunos no lo sabían- un refuerzo para una visión a menudo preciosista y a veces hagiográfica de la cultura aristocrática.

${ }^{16}$ El problema adquiere su dimensión en el seno de una «crisis de la aristocracia»-permítaseme usar el término un poco obsoleto sobre el que espero volver en alguna ocasión-, que tiene una dimensión especialmente cultural y en el que no podemos entrar aquí en detalle.

${ }^{17}$ Buena parte de lo que sigue tiene su trasfondo en el pensamiento económico de la Escuela de Salamanca, sobre la que todavía siguen siendo los mejores trabajos, a distancia, los estudios de Grice-Hutchinson. De ella se puede consultar con facilidad Grice-Hutchinson (1993).

${ }^{18}$ Valverde (1986), Carrasco (2002).
} 
ciedad, su sociabilidad, estaban condicionadas por su ubicación social. Consecuencia de ello era que la moral, la moral política y también la moral económica, eran profundamente conservadoras. La «novedad» era algo, de por sí y en principio, rechazable en la visión del mundo de la época, en tanto que apartaba a la sociedad del orden establecido ${ }^{19}$. Y consecuencia de ello asimismo era un hecho esencial que parece haber estado especialmente desarrollado en la Península -aunque ni mucho menos es, como a veces se piensa, un rasgo exclusivo de ella-: el status social y las características que lo acompañan -incluso el privilegio que depende de ella- son aspectos reconocidos por los demás en cada uno de los individuos. Se es noble, se tiene honor, en tanto que uno se comporta como tal y por ello se le reconoce como tal. La identidad era una identidad, permítaseme la expresión, con un fuerte componente de identidad «atribuida» por otros: un hecho esencial en la identidad aristocrática y nobiliaria en general de la época, y que se comprueba en el elevado valor que se da a la reputación en todo tipo de textos y, más en particular, en los tratados de educación de príncipes que tenían como objeto formar señores ejemplares cuyas virtudes impresionaran y fueran reconocidas por el resto de la sociedad ${ }^{20}$.

Por otra parte, la moral de la época e incluso otras muchas cosas más allá de ella estaban profundamente afectadas por la religión. De hecho, la propia moral aristocrática estaba indisociablemente unida a ésta hasta grados que a menudo han pasado inadvertidos incluso a quienes han estudiado el tema. Basta un vistazo a los manuales de confesores de la época para llegar a esta conclusión. Textos como el publicado en Salamanca por primera vez en 1556 -y abundantemente reeditado- por Martín de Azpilcueta, son un buen reflejo de todo ello. En su capítulo xxv y en breves sentencias, se van estableciendo en él cuáles son las obligaciones de un gran señor y el tipo de pecado -mortal, venial, etc.- en que puede incurrir si no las cumple. La propia gestión económica -si es que ésta se puede definir así- era fuertemente dependiente de una moral social y religiosa perfectamente establecida y, como veremos enseguida, tenía una dimensión moral, más allá de su función económica, consistente sobre todo en mantener la Casa y atender a las necesidades espirituales y materiales de los vasallos ${ }^{21}$.

${ }^{19}$ Levi (próximo). Sobre el carácter conservador de la cultura de la época y el papel, selectivo, de la novedad, se extendió hace tiempo también J. A. Maravall (2000).

${ }^{20}$ Sobre los tratados de educación de príncipes, textos esenciales en el sentido que apuntamos, puede verse la reciente obra de J. Meyer (2004).

${ }^{21}$ El capítulo citado (pp. 517-24) lleva por título «De algunas preguntas particulares, de algunos estados. Y primeramente de los Reyes, y señores, que en esta vida no tienen superiores, quanto a lo temporal». Como corresponde a la propia escuela de Salamanca y a la visión tomista de la moral política, el texto pretende claramente establecer los límites al poder tanto del Príncipe como de los señores -ambos asimilados obviamente aquí- en términos de pecado. Como es habitual en la época, el discurso se dispone en forma de casos, que se corresponden con preguntas a realizar tanto por el confesor como por el mismo confesado a manera de examen de conciencia, a los que se va calificando de pecado mortal o no y respecto de los cuales se van estableciendo los requisitos para su perdón. 
Las consecuencias de todo ello en el conjunto de normas sociales que supuestamente podían afectar a la gestión de los patrimonios y de la riqueza, y, particularmente, en la moral «económica» de la aristocracia, son de un alcance difícil de exagerar, y afectaban a todas las dimensiones de la vida. Por lo que a nosotros nos interesa, hay algunas que es inexcusable subrayar ${ }^{22}$.

Uno de los principales problemas era, sin duda, el de justificar la existencia de las desigualdades económicas y sociales $-\mathrm{y}$, consecuentemente, de la propia nobleza como tal- en un mundo en el que todos los hombres eran iguales ante Dios. Aunque a lo largo de la época moderna cristalizarían argumentos diversos, lo cierto es que la clave se ponía sobre todo en la imperfección del mundo terrenal y en la necesidad de que la comunidad y la religión fueran defendidas por algunos ${ }^{23}$. El estatuto de nobleza se ligaba así inextricablemente a la condición militar de ésta ya desde las propias raíces teológicas de su justificación. Por lo que se refiere a las riquezas acumuladas por algunos, y desde luego por la aristocracia, sólo su función social, es decir el utilizarlas en beneficio de los pobres y el bien de la comunidad, lo podía justificar. Se creaba así, ya de entrada, una moral de gestión patrimonial, que sería continuamente repetida por textos y manifestaciones coetáneas $^{24}$. Clave asimismo de la economía moral de la época y, particularmente, de la

${ }^{22}$ Permítanseme las comillas para expresar que no se debe buscar una moral económica como tal, pues realmente no existía, sino una serie de prescripciones normativas que afectaban a las reglas de conducta aristocrática en general y que, directa o indirectamente, más o menos según las circunstancias, y de forma diversa según éstas, podían afectar a la gestión de los patrimonios aristocráticos en múltiples esferas -consumo, inversión, relación con los vasallos...-. En otras palabras, el historiador de la economía inútilmente puede buscar algo así como lo que hoy llamamos una «moral de los negocios» o una «ética de los negocios». Lo que existía era una moral personal cuyos efectos sobre el funcionamiento de la economía podían ser muy diversos.

${ }^{23}$ Véase sobre todo Carrasco (1998). La idea, como es sabido, arranca ya de la época medieval.

${ }^{24}$ Tal opinión se encuentra en muchos de los tratadistas de la época, de Vives a Juan de Robles o Domingo de Soto. Por citar tan sólo un ejemplo, en uno de los diálogos escritos por Miguel de Giginta, su Tractado de Remedio de Pobres (1579), se mantenían dos opiniones contrarias, pero poniéndose especial énfasis en la segunda. Concretamente se decía:

«MARIO: Si los ricos viven de su hacienda propia bien ganada o heredada sin perder ni quitar a nadie, ¿por qué no podrán gastarlo en cuanto se les antojare, y aun echarlo por eso río abajo?

VAlerio: No es conveniente a la república ni lícito a ninguno que use mal de su hacienda, ni podéis llamar propio lo que gastáis o retenéis superfluamente, mientras haya prójimos que padecen extrema necesidad de ello, como sobran; cuyo es aquello entonces más propio que nuestro, porque cuanto tenemos nos da el Señor prestado, paran que sacado de ello necesario para nosotros y nuestra moderada familia, sobriamente viviendo, le volvamos el resto en su culto y pobres que tanta extremidad padecen. Por eso, desperdiciad a rienda suelta con olvido de vuestra obligación y veréis como llegaréis sin parar a donde cuando queráis dar vuelta, podría haber tan poco lugar como tuvo el mal rico por ello después de muerto.»

Giginta (2000, 146-7) 
economía moral de la nobleza y de la aristocracia era el concepto, tan brillantemente defendido por Bartolomé Clavero, de «antidora», según el cual las relaciones humanas y particularmente las de amistad estaban presididas durante la época moderna por criterios cercanos a los del regalo y el don y muy lejanos a los del beneficio crematístico ${ }^{25}$.

De acuerdo con todo lo anterior, no es extraño que se entendiera que la principal obligación de príncipes y señores fuera la protección y el mantenimiento de sus vasallos, lo que, además, generaba una relación paternalista que les comprometía a ambos ${ }^{26}$. El uso de las riquezas estaba limitado por este hecho. Ni a los vasallos se les podía pedir, por prestado o por extorsión, más de lo que ese mantenimiento de éstos imponía, ni se podía acumular a su costa, ni el gasto se podría orientar hacia lujos a costa de la comunidad, ni éste era posible más allá del propio sustento y de la casa, si no era para el bien de aquéllos. Incluso el endeudamiento, que por otra parte no se consideraba sino como un acto antidoral al que se correspondía otro del mismo tipo, como es la devolución de la cosa prestada, era nocivo si se practicaba a riesgo de extorsiones para con los vasallos ${ }^{27}$.

${ }^{25}$ Curiosamente, y sin citarlo, lo que no deja de ser buena prueba de la falta de sensibilidad de otras historiografías hacia producciones más localizadas en el ámbito ibérico, el concepto ha sido después retomado por N. Zemon Davis. Véanse Clavero (1991) y Davis (2000). El tema fue también desarrollado más directamente en el contexto de las relaciones de amistad que existían en la aristocracia por Jouanna (1989), pp. 64-116.

${ }^{26}$ Ya hace tiempo subrayada también por el propio Thompson como una de las claves de las relaciones entre patricios y plebeyos, y de la que incluso éstos se sentían imbuidos. La literatura, e incluso las manifestaciones alegóricas y artísticas, son inagotables en este punto.

${ }^{27}$ El texto de Azpilcueta es significativo en ese sentido. Entre las preguntas que todo confesor había de hacer a los príncipes y señores se trataba de saber «si fue tan notablemente negligente [...] en proveerlos de lo necesario para bivir» o si «puso en peligro notable defender su republica o parte de ella», "si fue tan notablemente negligente en procurar de atesorar riquezas artificiales de oro, plata, dineros, y otras semejantes, que se puso en peligro provable de no poder proveer a su reyno, en las grandes necesidades de hambre, guerras, pestilencias, que probablemente se devian temer: o en peligro provable de tomar prestado de sus subditos con afrenta, empacho, y daño notable de su acatamiento, o de la justicia, que creya, o devia creer, se seguiria en los nobles subditos y señores que le prestasen. $\mathrm{O}$ en peligro de pagar grandes intereses, con agravio de los pobres subditos, a los mercaderes subditos o estraños, que se lo diessen a interesse», «si ayunto tesoros con agravio notable de sus vasallos y aun sin agravio de otros por codicia, sin fin de proveer a las necesidades publicas, ni privadas, según S. Ant. Porque quien asi atesora, proposito tiene de no dar lo superfluo a los pobres, que no es mandado, como arriba se dijo». "Si gasto mas de lo que le rentan sus rentas en mercedes y cosas desnecesarias, poniendose en tal necesidad que creia le haria tomar lo ageno injustamente o dejar de pagar sus deudas a los tiempos asentados, sin consentimiento libre (a lo menos tacito) de sus acreedores o con su consentimiento dañoso mucho a su real estado, y a la republica que lo ha de mantener, por los grandes interesses, que le llevan y con que lo empobrecen» (pp. 519-20). 


\section{EXPERIENCIAARISTOCRÁTICA EN LA ÉPOCA DEL QUIJOTE}

Sin embargo, sería la combinación de esta moral económica y la propia experiencia aristocrática en una etapa de tensa remodelación de los valores sociales lo que habría de guiar la actuación de la nobleza en la época de El Quijote ${ }^{28}$.

Es importante en ese sentido tener en cuenta que, contrariamente a lo que se viene diciendo, no era la nobleza -ni tampoco la aristocracia castellana- un grupo monolítico, y a salvaguarda completa de las transformaciones sociales y culturales de la época. Por el contrario, los cambios económicos, sociales y en la propia cultura aristocrática estaban sometiendo a los nobles e incluso también a los señores a una tensión sin precedentes, en cuyas distintas facetas no podemos entrar ahora. Hay, sin embargo, una serie de aspectos que cabe retener y que apuntan hacia la existencia de una aristocracia poderosa, pero mucho más débil y en entredicho de lo que se ha pensado.

Sin duda, y como en toda Europa, uno de los factores más importantes era el aumento del número de títulos -y de nobles-, un hecho éste que ponía en entredicho el status de todos y que hacía más difusas, amplias y de resultado más incierto las relaciones internas dentro de la alta nobleza. El hecho había sido paralelo a la emergencia de los letrados, al desarrollo de la vida cortesana y al proceso de urbanización, que creaban asimismo un alto grado de inseguridad -se nos llega a describir incluso en términos de angustia — y generaba espacios de sociabilidad en los que había que crear y reproducir la propia imagen, lo cual es de vital importancia en una sociedad en la que, como hemos dicho, las virtudes, pero sobre todo la honra y el honor, se poseían como atribuidas por otros; y donde, además, ambos eran las claves del privilegio y las mercedes del Rey ${ }^{29}$. En definitiva, en estos nuevos espacios de sociabilidad y de comunicación social, mantener la propia imagen de uno como noble, como título, como grande, reproducir el propio capital inmaterial, era no sólo más necesario, sino incluso más difícil o, simplemente, forzaba a líneas de actuación hasta entonces no ausentes pero sí menos practicadas entre la clase señorial.

Todo ello se combinaba con un notable dinamismo social. El ascenso no ya sólo de los miembros del grupo mercantil, al que siempre nos referimos con una imagen por cierto anacrónica, sino también y sobre todo de ramas menores de la nobleza, de los patricios urbanos, su notable poder social y político, no hacían

${ }^{28}$ Aunque, como se verá, la «encrucijada» por la que atraviesa la aristocracia se plantea aquí de otro modo, el lector interesado podrá encontrar una buena descripción y un muy bien documentado trabajo a este respecto en García (2000).

${ }^{29}$ Sobre los distintos componentes e implicaciones del honor en la España del siglo de Oro, debe verse Chauchadis (1984). Particularmente, para la relación entre honor, virtud, privilegio y mercedes del Rey, en pp. 50 y ss. y 110 y ss. 
sino agudizar las tensiones. Las pruebas son abundantísimas, pero baste con llamar la atención en ese sentido sobre la continua queja de nobles y moralistas -y, por supuesto, también del pueblo llano- respecto al «desorden» social o, lo que es lo mismo, respecto a la trasgresión social, evidente sobre todo en la permanente ruptura de los códigos de conducta; una novedad, desde luego, inadmisible para muchos. La literatura de la época, y el mismo Quijote, están plagados de este tipo de queja ante la movilidad y el dinamismo que afectan a las fronteras entre los nichos sociales ${ }^{30}$. Por poner tan sólo un ejemplo más particular, las leyes suntuarias por las que se luchaba contra el lujo son, en parte, la manifestación del intento de atajar una trasgresión, la del lujo de los plebeyos, que atentaba contra el código de distinción de la nobleza y convertía a ésta en una categoría cada vez más dudosa ${ }^{31}$.

Por si ello fuera poco, la propia nobleza e incluso la aristocracia estaban aquejadas de problemas, sobre todo económicos. Es sabido el alto grado de endeudamiento que todas las casas de la alta nobleza alcanzaron en las últimas décadas del siglo XVI. Y aunque es cierto que en el código antidoral de la época estas deudas -sobre todo las que se manifestaban en forma de censos- más que deudas eran favores que se devolvían con favores -a veces la simple restitución del préstamo-, no por ello dejaban de suponer un cierto desdoro cuando llegaban a ciertos límites. De hecho, así se vivían por muchos nobles, en especial cuando llevaban al secuestro de sus estados por parte del Rey o las Chancillerías. La deuda y el empeño, si bien eran manifestación del alto «crédito» de la aristocracia ${ }^{32}$, testimoniaban asimismo la menor capacidad de movilización económica, directamente relacionada con la capacidad de servir al Rey y, por tanto, de cumplir con la obligación más importante con respecto a éste y a la comunidad: la prestación del auxilium. Igualmente, y en buena medida por las mismas razones, las deudas iban contra un componente de la nobleza, la riqueza, que si bien no se identificaba con ella, le era consustancial. En otras palabras, incluso las deudas en forma de censos, por no hablar de las deudas sobre bienes libres, aún más peligrosas por sus

\footnotetext{
${ }^{30}$ Entre la multitud de pasajes al respecto, recuérdese, por ejemplo, el del relato sarcástico que Cervantes pone en boca de un loco como Don Quijote cuando éste se refiere al linaje de Dulcinea, al fin y al cabo una campesina a la que se le crea una familia y una historia familiar en cierto punto similar a la de las más grandes casas de Castilla o Aragón: Cervantes (2004), Primera Parte, Capítulo XIII, p. 155.

${ }^{31}$ A este respecto véase sobre todo el estudio clásico de Viñas Mey (1970). Por supuesto, también la nobleza titulada y los grandes eran objeto de las leyes contra el lujo -y lo mismo ocurría con las manifestaciones de las Cortes-, por razones evidentes y porque no dejaba de ser una práctica perjudicial a la república.

${ }^{32}$ El término fue agudamente analizado por A. Jouanna (1989), pp. 64 y ss. Según señala, el crédito tenía que ver con la solvencia que uno era capaz de mostrar y era igual asimismo «al número de 'amigos’ que se podían juntar en torno a una persona» (p. 64). En otras palabras, «crédito» y capacidad de crear y movilizar clientelas eran dos conceptos a menudo superpuestos.
} 
efectos económicos directos, erosionaban el prestigio de una clase a la que era incluso honroso prestar, pero cuya legitimidad social se veía así disminuida ${ }^{33}$.

Para fines del siglo xvi, el Rey había conseguido asimismo un alto poder sobre la nobleza que afectaría de manera muy notoria a los comportamientos de ésta. He intentado explicar en otras ocasiones que, en realidad, existía una dependencia mutua, no sólo en el plano político o militar, sino también en el económico, que no siempre ha sido captada por los historiadores ${ }^{34}$. Pero no es menos cierto que, si esa dependencia era mutua entre la Corona y la aristocracia como grupo, en el plano de la experiencia y de la acción diaria, siempre individuales, el hecho revertía en una sujeción de las distintas familias hacia el Rey. En otras palabras, si Felipe II necesitaba a la nobleza tanto como la nobleza a él, el Conde de Benavente, por poner un ejemplo,

${ }^{33}$ Son muchos los ejemplos que podríamos citar al respecto. Si, a fines del xvi, el Duque de Béjar escribía al Rey a propósito de sus deudas «que no quería que lo supiesen los extraños, porque no está bien a mi crédito que entiendan que soy tan pobre»-cit. por Jago (1982)-, obviamente, el Duque usaba la palabra crédito en el doble sentido apuntado por Jouanna. Se es persona de «crédito" cuando se es persona fiable y segura o, en otras palabras, se tiene este tipo de honra. Curiosa y paradójicamente, lo que está diciendo es que el exceso de créditos deudas que ha podido contraer por ser persona de crédito- le está mermando su imagen social más allá de sus cercanos.

Pero, como en tantas ocasiones, basta recurrir a El Quijote para encontrar los mejores ejemplos. Los pasajes a este respecto son abundantes, pero mírese tan sólo uno de los poemas iniciales:

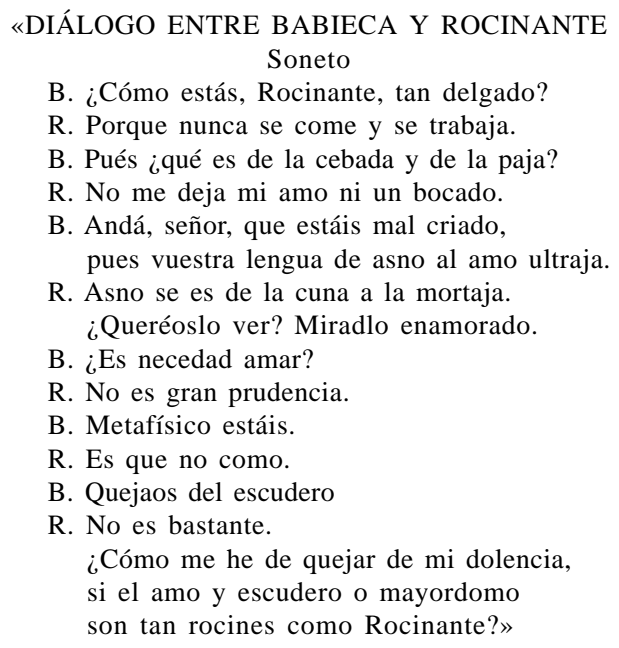

Hasta el propio Rocinante, desde luego muy por debajo de las circunstancias, puede contar la deshonra de su señor debido a la falta de riquezas de éste, que lo llega a postrar incluso en el hambre. Cervantes (2004), pp. 35-36.

${ }^{34}$ En particular, esta idea de la dependencia de la aristocracia respecto de la Corona, en especial en el plano financiero, fue subrayada en su día por Jago (1973). 
le necesitaba a él más que al contrario. De hecho, el alto poder de arbitraje de la Corona en las relaciones intra-nobiliarias le daba a ésta una gran capacidad de acción, materializada si era necesario incluso en el «divide y vencerás». Al mismo tiempo, cada una de las grandes casas, individualmente, dependía de forma muy notable de la Corona: el Rey debía aprobar sus casamientos, el Rey ratificaba sus censos, el Rey decidía el secuestro de sus estados, el Rey daba mercedes y los oficios, cada vez más necesarios en una situación de dificultades financieras y de reproducción del poder de la casa. Ello no era sino un complemento de un proceso que, con más o menos diferencias, era general a toda Europa: el creciente control por parte de la Corona del acceso a la nobleza y, sobre todo, a los títulos y a la Grandeza, en buena medida creada a esos efectos ${ }^{35}$. La cultura aristocrática y, con ella, su economía moral no dejarían de verse afectadas por este hecho.

Ello creaba un plano de acción, el de la política y el de la Corte, como espacio de sociabilidad y de poder, de no menor impacto sobre la praxis aristocrática. En el mundo de la clientela y el patronazgo, que era también el de las alianzas entre familias, la fuerza de éstas estaba precisamente en el mantenimiento de sus lazos de solidaridad y reciprocidad. El fenómeno no era nuevo. Por el contrario, es también una constante de las relaciones intra-aristocráticas desde la época medieval. De hecho, estas venían presididas por la necesidad de mantener unidos los linajes y de crear lazos de solidaridad entre ellos $^{36}$. Pero no es menos cierto que el reforzamiento del patronazgo de la Corona, la extensión de su poder e influencia, creaba un espacio de confrontación política en el que proyectarse y que afectaría a la moral y a la economía moral de la alta nobleza. Un espacio en el que mantener el linaje, y en el que reproducir y reforzar el linaje era al mismo tiempo una necesidad inexcusable y un requisito para satisfacer esa necesidad ${ }^{37}$. Y, desde luego, un espacio que abría otros muchos, pues la proyección sobre la Corte era el trampolín para abrir horizontes, enlazar con nuevas clientelas y familias y reproducir política y socialmente la propia en los confines de un imperio plurinacional; y ello aun a costa de crear nuevas tensiones en las distintas casas, cuya dispersión no dejaba de alimentar una tendencia centrífuga de gran relevancia ${ }^{38}$.

Por si fuera poco, el cambio cultural que arranca del Humanismo había creado nuevas condiciones para la experiencia aristocrática. De hecho, es en ese contexto donde se debe entender la eclosión de los llamados valores burgueses: un diferente sentido del ocio y del trabajo que llevó a algunos moralistas a la elaboración de una cierta casuística más tolerante en este sentido y que admitía la posibilidad de traba-

\footnotetext{
${ }^{35}$ Véase sobre todo a este respecto Jouanna (1991).

${ }^{36}$ Yo mismo he hecho de este tema una de las claves de la dinámica social de la aristocracia en la época moderna (2002).

${ }^{37}$ Como la anterior, ésta es una cuestión bien conocida. Véase, por ejemplo, Yun (2002).

${ }^{38}$ Véase Redondo y Yun (próximo).
} 
jos que no implicaban la pérdida de la nobleza ${ }^{39}$; una recuperación de la crítica al lujo -que, como hemos visto, estaba presente incluso entre los moralistas de la Escuela de Salamanca ${ }^{40}$-; el sentido de una nobleza no sólo dedicada a las armas sino también a las letras, evidente sobre todo en Erasmo. A todo ello habría que añadir una necesidad creciente de justificarse por las obras, un aspecto, a menudo olvidado por lo demás, que habría de tener no poca importancia y que implica un reforzamiento del sentido del mérito, cada vez más desarrollado, a medida que se extendía el debate en relación a la necesidad o no de «renovar» la nobleza recibida de los antepasados merced a las propias acciones. Para entender la importancia de esta cuestión conviene subrayar, además, que se trata de una idea con fuerte sentido religioso, que enlaza con el problema del libre albedrío y la redención por las obras abierto por el luteranismo; un hecho central en las controversias religiosas -y, por tanto, que afectaba a todas las esferas de la vida social-y que, para fines de siglo, habría impregnado todos los poros del tejidos social. Es una auténtica constante en El Quijote, para cuyo personaje central, el valor de las obras y el «deshacer entuertos y agravios», esenciales en la literatura caballeresca, son las claves principales de comportamiento. No es extraño si consideramos que éste es el momento, últimas décadas del siglo xvı, del gran debate que tuvo sus dos grandes protagonistas en el Padre Báñez, por un lado, y el Padre Luis de Molina, por el otro, y en el que se discutía precisamente sobre el valor real de las obras humanas ${ }^{41}$. Una discusión ésta que traspasó claramente el escenario de los teólogos para proyectarse sobre toda la sociedad e incluso el teatro de la época, el medio de comunicación más popular de las ciudades de Castilla y Aragón. Es difícil no imaginar a la nobleza católica de entonces -y en parte a la no católica-, por lo demás muy influida por los jesuitas, tan presentes en estas contiendas, como un grupo muy pendiente de la necesidad de las obras; y ello por razones de tipo político -por las obras se obtenían las mercedes-, religioso -por ellas se alcanza o no la salvación- y ético -por ellas se confirmaba la nobleza de los antepasados y se manifestaba la virtud.

\section{ECONOMÍA MORAL Y GESTIÓN ARISTOCRÁTICA}

El resultado de estas experiencias aristocráticas y su relación con la moral -contradictoria a menudo, pero también complementaria, como veremos-, así como de

${ }^{39}$ Juan de Pineda (1589, p. 125) expresaba abiertamente que

«No es de nobles y poderosos ir a trabajar a las heredades ajenas, mas no se pierde la nobleza por ir a las suyas y echar mano de algo para más avivar los ánimos de los trabajadores, y para mirar por su hacienda y ordenar como ha de ir cada cosa, pues, como dijo el otro prudente, no hay mejor estiércol para la heredad que la huella de su dueño».

${ }^{40}$ Chauchadis (1986), p. 117.

${ }^{41}$ Para una visión general, que refiere también la proyección social del debate, véase Valverde (1986), pp.97-102. 
las características económicas de los patrimonios aristocráticos, era una economía moral que no dejaría de pesar sobre las formas de gestión ${ }^{42}$.

Es evidente, en contra de lo que han sido los tópicos sobre el «estilo de vida aristocrático», que la alta nobleza peninsular, y desde luego la castellana, mantuvo un interés permanente en hacer mucho más rentable la gestión de sus patrimonios. Esto era necesario para subsistir en un mundo como el descrito. Y no debe extrañar en ese sentido la introducción de mejoras agrarias o la solicitud de permisos de censo para mejoras en los mayorazgos, un hecho éste ignorado por la historiografía económica durante mucho tiempo. Cabe añadir que éstos se concedían por parte del Rey -y se presentaban como justos por parte de los solicitantes- en función de una moral económica según la cual la principal función de los señoríos era el mantenimiento de los súbditos. Moral y necesidad eran, como en tantos otros casos, dos caras de la misma moneda -o, al menos, así se las presentaba-. Se entiende también que, en la medida en que era posible, se mantuviera un cierto grado de flexibilidad en la gestión de los señoríos, aunque, como veremos, esto pudiera tener otras consecuencias.

Pero es asimismo explicable que los criterios de gestión señorial no se puedan entender tan sólo desde la consideración de la vertiente del señorío. Como he comentado en otra ocasión, los patrimonios señoriales estaban compuestos de una doble esfera, la del señorío y la de otros muchos recursos, algunos de ellos fruto de un voluminoso capital inmaterial y político que daba lugar a estrategias de gestión «político-social»; es decir, que iban orientadas a la promoción de la casa y de la familia en el plano político. No es extraño, en cualquier caso, que también en este sentido lo que encontramos sea una adaptación entre moral y necesidad, entre experiencia y valores culturales, por decirlo con las palabras de E. P. Thompson. Por una parte, esas estrategias -materializadas en la promoción política y social de miembros del linaje, en elevados gastos de servicio al Rey o en gastos de «representación», etc.- eran necesarias e incluso generaban líneas de gasto que más bien se aproximaban a formas de inversión. De ellas dependía la solidez del linaje o de la casa, tan importantes entonces; de ellas dependía asimismo la promoción política en el seno del sistema de poder del Imperio que giraba en torno a la Corte, etc. Pero ellas tenían mucho que ver con la convicción moral de que en la época, las obras, las que llevaban a cabo los nobles al servicio del Rey y de la comunidad, eran la clave de su prestigio y de su condición, constituían un modo de renovar la nobleza y de practicar la virtud. El interés personal se mezclaba con el código moral, y el código moral se adaptaba a aquél, e incluso conformaba el lenguaje en que éste se presentaba. Gigantes y molinos, condicio-

\footnotetext{
${ }^{42} \mathrm{Me}$ he referido a esto en diversas ocasiones. Véase, por ejemplo, Yun (2005). Por esa razón, también abrevio aquí el aparato crítico ya citado en esos otros textos y abrevio explicaciones en muchos sentidos.
} 
nes materiales y códigos de conducta, se complementaban y fundían como si fueran la misma cosa.

El fenómeno es aún más claro si lo planteamos desde la perspectiva del gasto aristocrático, como también he comentado en otras ocasiones, algo que era asimilable a la inversión y que constituía la variable independiente de la gestión señorial. El lujo -como la sobriedad en algunos $\operatorname{casos}^{43}$ - sin duda una de las manifestaciones de los criterios de gasto, tenía su función y su justificación, ambas indisociablemente unidas e interfiriendo entre sí en el concepto que la sociedad creaba al respecto. De hecho, el lujo era una manifestación de poder, de riqueza, de «crédito», impuesta por la estrategia política de gestión, pero se derivaba asimismo de la necesidad de recrear y reforzar la imagen en los nuevos espacios de sociabilidad de las ciudades y de la Corte en particular, por las razones ya indicadas. Como también lo serían en su momento sus opuestos, el apartamiento y el estoicismo, el lujo y las manifestaciones externas de riqueza eran, aparte de otras muchas cosas, una reacción y una forma de afrontar el conflicto personal que creaba la Corte como espacio de sociabilidad y en el contexto de la trasgresión social permanente. Pero, aparte de ello, tenía su lógica económica irrefutable en el sistema de doble economía que conformaban la conjunción de «mayorazgos» y bienes libres no sujetos a regulación y alimentados por ingresos políticos ${ }^{44}$. Y la tenía tanto más cuanto que las posibilidades de inversión en el señorío eran a menudo limitadas o no siempre posibles sin un alto grado de conflicto debido a la propia estructura de la renta señorial y al sistema de los derechos de propiedad. En una sociedad en la que las apariencias tenían tan alto valor en la atribución de status social y en la que éste estaba tan regulado, todo ello no era cuestión baladí. Si se podía gestionar conforme a la economía moral, hacerlo era algo más que un vicio: era una forma de virtud.

Estas formas de economía moral y su plasmación en la gestión aristocrática tenían un doble efecto. Por una parte, era imposible evitar el efecto emulación derivado de los comportamientos de un grupo social dominante. Por otra parte, y aunque en apariencia de modo contradictorio, tenían un efecto boomerang, en la medida en que se volvían incluso contra la propia clase social. La consideración de ambos nos permite una mejor comprensión de las acciones sociales y sus implicaciones económicas en la época y nos sirve para resolver algunas de las paradojas de la España -yo diría que de la Europa- del Quijote.

\footnotetext{
${ }^{43} \mathrm{~N}$ i los historiadores de la economía ni los historiadores sociales se han ocupado hasta ahora de la sobriedad aristocrática, un hecho de gran importancia en algunos momentos e individuos del Siglo de Oro y particularmente de la época de Felipe iI como forma de posicionamiento moral y social. La carencia de estudios en este sentido entre los historiadores de la economía es perfectamente justificable por razones que no vienen al caso; no así ocurre en el caso de los historiadores de la sociedad y la política.

${ }^{44}$ Particularmente, véase Yun (2002).
} 
El primero es en parte conocido: el deseo de aparentar y mostrar riqueza, el lujo, el «estilo de vida noble» -por decirlo en la forma convencional tradicionalsobrepasaba la esfera de la nobleza y de la aristocracia y se convertía en algo a imitar. Es precisamente lo que los historiadores hemos tenido en mente cuando hablamos de la trayectoria social de los grupos emergentes a fines del xv y, sobre todo, de los mercaderes y hombres de negocios.

El segundo es menos habitual entre nosotros: el resultado de la economía moral aristocrática y de las formas de gestión era una serie de contradicciones sociales y culturales que, lejos de ayudar a superar la encrucijada en que se hallaba la nobleza, no harían sino alimentar las tensiones identitarias en su seno y en relación con el conjunto de la sociedad. Y ello tanto más cuanto que sus comportamientos transgredían a menudo la moral económica. Así, los deseos de mejorar la gestión de los señoríos chocaban a menudo con los derechos de los vasallos, el endeudamiento iba no pocas veces en contra de los intereses de éstos, la utilización de la riqueza en beneficio propio y el lujo no dejaban de provocar tensiones entre la práctica y las prescripciones de los moralistas a que antes nos hemos referido. Tales «pecados» no sólo eran vistos por el resto de la sociedad, sino también por otros muchos príncipes y señores ${ }^{45}$. Los veían en sí mismos y en los otros, dependiendo de las situaciones y de las coyunturas. En el contexto de las tensiones antes descritas, todo ello no era sino la base de una introspección moral que no dejaría de afectar a los propios valores sobre los que se vertebraba la nobleza y que creaba una situación muy lejana a la imagen de una cultura aristocrática inamovible, sólida, imitada sin contestación, a la que la historia reciente nos tiene acostumbrada ${ }^{46}$. El resultado sería, de hecho, una reformulación de la aristocracia y, sobre todo, de sus representaciones como clase, que está todavía por hacer en el caso de la historia de España

\footnotetext{
${ }^{45}$ Un ejemplo de este tipo de introspección podemos encontrarlo en el famoso texto de Doña Luisa María de Padilla, noble aragonesa e interesantísimo personaje aún por estudiar hasta donde yo sé, que dedicó a sus congéneres un interesante tratado, modelo de prédica comedida sobre la gestión de la casa y que no hacía sino retomar el discurso de la Escuela de Salamanca. Así decía, doña Luisa (1644, pp. 231-32):

«Ni ha de ser el noble miserable ni pródigo porque desordenados deseos se transforman en necesidades y son heridas mortales al mayorazgo [...] La casa y la renta se han de medir con las rentas y se ha de ajustar el gusto al poder.»

Un auténtico alegato no sólo contra el lujo, los excesos y la extorsión de los vasallos, sino también sobre la regla que hacía del gasto la variable independiente y del ingreso algo que había de adaptarse a aquél y que durante siglos -y, en muchos casos, en adelante también- había regido la lógica de gestión de las casas señoriales.

${ }^{46}$ El fenómeno, como es sabido, no es exclusiva de la nobleza, sino una constante en toda la sociedad española: véase Elliott (1990). Lo que llama la atención es que, en ese contexto de todos reconocido, pocas veces -por no decir casi nunca- se ha pensado que esa introspección afectaba de lleno al grupo cultural, social y económicamente dominante cuyos valores -precisamente los que criticaban los arbitristas, entre otros- se proyectaban tan de lleno sobre el conjunto social.
} 
y cuya consideración nos llevaría muy lejos aquí. Y, desde luego, las críticas arreciarían de forma sistemática, tanto del lado de los así llamados arbitristas, que, como González de Cellórigo, Caxa de Leruela y tantos otros, se quejaban, según fuera el caso, lo mismo del abandono de sus explotaciones que de las extorsiones a los vasallos, como del lado de los tratadistas de la época, para los que la distancia entre la teoría moral y la práctica social era cada vez mayor.

Nada más lejos de unos valores aristocráticos inamovibles y fijos. Por el contrario, éstos eran contradictorios entre sí e incluso creaban incomodidades y algún desasosiego a los miembros de dicha clase. Lo que se estaba produciendo era una convulsión de dimensiones a menudo ignoradas por los historiadores; una convulsión que afectaría incluso a su propia cultura y cuyas dimensiones, trascendencia y profundidad nos son aún desconocidas. No es éste el lugar para estudiarla. En todo caso, interesa subrayar que no parece que la realidad permita divisiones tan rígidas como las que a menudo hemos hecho entre mentalidad aristocrática y mentalidad burguesa, y que, sin ser incorrectas, constituyen arquetipos de carácter instrumental más que realidades fijas. La atracción por el estilo de vida señorial de que hemos hablado durante años tenía como contraprestación un debate en el seno de la sociedad española que impregnaría también a la aristocracia y que nos obliga a plantear el tema de otro modo.

Lo que muestran los hechos es que la acción social no se entiende sino como el resultado de «experiencias materiales [que] se modelan en formas culturales» -y, permítaseme añadir, «y viceversa»-. Desde esa perspectiva, la gestión de los grandes patrimonios señoriales se puede entender más allá del mundo de los valores o de la historia intelectual aislada, y también más allá de las consideraciones de un cierto tipo de historia económica que peca de anacrónica por cuanto intenta explicar las conductas del pasado sin contextualizarlas en la confluencia entre el sistema de valores y las experiencias sociales. El hecho puede ser de gran importancia para entender la crisis del siglo xvir en Castilla -y en España e incluso Europa en general-, más allá de un debate simplista que ha puesto el acento, de un lado, en los códigos de conducta desde una perspectiva teórica y, del otro, en la toma de decisiones que se configuran estrictamente en el plano de la economía-o, mejor dicho, de lo que a nuestros ojos es la economía-. Es el diálogo entre historia cultural e historia económica el que nos puede ayudar a entender la trascendencia final de todo esto para el desarrollo económico. La vuelta a la historia cultural y la vuelta a la integración de ésta en las explicaciones económicas debe, pues, hacerse de un modo diverso a lo que planteamientos trasnochados puedan haber dado lugar, lo que es especialmente importante cuando se trata de analizar las causas del así llamado «atraso español», cuyo arranque se suele situar algunas veces en torno a estos años y en torno a alguno de los problemas que hemos referido.

Permítaseme añadir que me parece difícil entender El Quijote -o, si se prefiere, hacer una lectura de él desde la perspectiva de la historia social y económica- 
fuera de estas consideraciones; y aun más difícil me parece entender la historia de la aristocracia y, por ese conducto, las historia económica de la España del siglo de Oro.

\section{BIBLIOGRAFÍA}

Álamos Barrientos, B. (1990) [1598]: Discurso político al rey Felipe III al comienzo de su reinado. Edición de Modesto Santos. Madrid.

AzPILCUETA, M. DE (1556): Manual de confesores y penitentes, que clara y brevemente contiene la universal y particular decisión de quasi todas las dudas que las confesiones suelen ocurrir de los pecados, absoluciones, restituciones, censuras, e irregularidade. Impresso en Salamanca, en casa de Andrea de Portonoariis, impressor de la S.C. Magestad.

V. E. Bonnell y L. Hunt (eds) (1999): Beyond the cultural turn: new directions in the study of society and culture. Berkeley.

Brantlinger, P. (2004): «A response to Beyond the Cultural Turn». American Hsitorical Review 107 (5), online sin paginar.

CARrasco, A. (1998): «Herencia y virtud. Interpretaciones e imágenes de lo nobiliario en la segunda mitad del siglo XVI», en Las sociedades ibéricas y el mar a fines del siglo XVI, Tomo IV, La corona de Castill. Madrid, pp. 231-272.

- (2000): Sangre, honor y privilegio. La nobleza española bajo los Austrias. Barcelona: Ariel.

Cavillac, M. (1994): Pícaros y mercaderes en el Guzmán de Alfarache. Granada: Universidad de Granada.

Chauchadis, C. (1986): Honneur morale et societé dans l'Espagne de Philippe I, París: Éditions du CNRS.

Clavero, B. (1991): Antidora. Antropología católica de la economía moderna. Milán: Universitá di Firenze.

Davis, N. Z. (2000): The gift in sixteenth-century France. Maddison: Wisconsin University.

Dewald, J. (1996): The European nobility, 1400-1800. Cambridge, Cambridge University Press.

ElliotT, J. H. (1990): «Introspección colectiva y decadencia en la España del siglo xvII», en España y su mundo, 1500-1700. Madrid: Alianza, pp. 287-311.

GARCíA, D. (2000): La aristocracia en la encrucijada La alta nobleza en la Monarquía de Felipe II. Córdoba: Universidad de Córdoba.

GiginTA, M. DE (2000) [1579]: Tratado de remedio de pobres. Edición y estudio introductoria de F. Santolaria Sierra. Barcelona: Ariel.

Grice-Hutchinson, M. (1993): Ensayos sobre el pensamiento económico en España. Madrid: Alianza editorial.

HAZARD, P. (1941): La crisis de la conciencia europea. Madrid.

JAGO, C. (1973): «The influence of debt on the relation between Crown and Aristocracy in Seventeenth Century Castile». Economic History Review 26, pp. 218-236.

- (1982): «La 'crisis de la aristocracia' en el siglo Xvir en Castilla», en J. H. Elliott (ed.), Poder y sociedad en la España de los Austrias. Barcelona, Crítica, pp. 248-86. 
Jounnna, A. (1991): «Des 'gros et gras' aux 'gens d'honneur'», en G. Chaussinnad-Nogaret, Histoire des élites en France du $X V I^{e}$ au $X X^{e}$ siécle. París: Éditions Tallandiers, pp. 17143.

LANDES, D. (1998): The wealth and poverty of nations. Why some are so rich and some so poor. Londres: Little Brown and Company.

Le Goff, J. (2004): Il cielo sceso in terra. Le radici medievale dell'Europa. Roma-Bari: La Terza.

Levi, G. (próximo): «Reciprocidad, equidad e imparcialidad entre la Edad Moderna y la edad Contemporánea», en B. Yun Casalilla (ed.), Andalucía en la encrucijada. Sevilla: Fundación José Manuel Lara.

Maravall, J. A. (1948): El humanismo de las armas en Don Quijote. Madrid: Instituto de Estudios Políticos.

- (2000) [1975]: La cultura del Barroco, Barcelona. Barcelona: Ariel, 8 a edición.

Meyer, J. (2004): L'éducation des princes en Europe. Du XV au XIXe Siècle. París: Perrin.

MокуR, J. (2004): «The intellectual origins of modern economic growth», texto presentado en el Instituto Universitario Europeo de Florencia. Transatlantic programme, 12 de octubre 2004 (en curso de publicación en Journal of Economic History).

Padilla, L. M. (1644): Ideas nobles y su desempeño en aforismos. Zaragoza.

Pineda, JuAn de (1589): Los Treynta y cinco diálogos familiares de la agricultura cristiana. Salamanca: Pedro de Adurça y Diego López.

Redondo, A, y Yun, B. (próximo): «Aristocracias, identidades y espacios políticos en la monarquía compuesta de los Austrias. La Casa de Borja (ss. Xvı y XvII)», en Homenaje a Don Antonio Domínguez Ortiz. Granada: Universidad de Granada.

SOMBART, W. (1966): Le bourgeois: contribution à l'histoire morale et intellectuelle de l'homme economique moderne. París : Payot.

- (1979): Lujo y capitalismo. Madrid: Alianza Editorial.

Suny, R. G. (2002): «Back and Beyond: Reversing the Cultural Turn». The American Historical Review 107 (5), pp. 1476-1499 .

Temin, P. (1997): «Is it Koser to talk about culture?». The Journal of Economic History 57 (2), pp. 267-87.

THompson, E. P. (1979): Tradición, revuelta y conciencia de clase. Estudios sobre la crisis de la sociedad preindustrial. Barcelona: Crítica.

- (1980): La formación de la clase obrera en Inglaterra. Barcelona: Crítica, 2 vols.

- (1995): Costumbres en común. Barcelona: Crítica.

VALVerde, C. (1986): «La Filosofía», en Historia de España fundada por Ramón Menéndez Pidal, Vol. XXVI* El siglo del Quijote (1580-1680). Religión. Filosofía. Ciencia. Madrid: Espasa Calpe, pp. 78-158.

VIÑAS, C. (1970): «Notas sobre primeras materias, capitalismo industrial e inflación en Castilla durante el siglo xvı». Anuario de Historia Económica y Social 3 (enero-diciembre).

VILAR, P. (1974): «El tiempo del 'Quijote'», en Crecimiento y desarrollo. Economía e Historia. Reflexiones sobre el caso español. Barcelona: Ariel, pp. 332-346.

Weber, M. (1978): Economy and society: an outline of interpretive sociology. Berkeley: University of California.

Yun, B. (1999): «La historia económica por el lado de la demanda y el consumo: unas reflexiones generales», en J. Torras y B. Yun (dirs.), Consumo, condiciones de vida y 
comercialización. Cataluña y Castilla, siglos XVII-XI. Valladolid: Junta de Castilla y León, pp. 9-23.

- (2002): La gestión del poder. Corona y economías aristocráticas en Castilla. Siglos XVIXVIII. Madrid: Akal.

- (2004): Marte contra Minerva. El precio del Imperio español, c. 1450-1600. Barcelona: Editorial Crítica.

- (2005): «From political and social management to economic management? Castilian aristocracy and economic development, 1450-1800», en P. Janssens y B.Yun-Casalilla (eds.), European aristocracy and colonial elites. Patrimonial management strategies and economic development, 15th-18th Centuries. Londres: Ashgate. 